\title{
Restriction site polymorphism-based candidate gene mapping for seedling drought tolerance in cowpea [Vigna unguiculata (L.) Walp.]
}

\author{
Wellington Muchero $•$ Jeffrey D. Ehlers • \\ Philip A. Roberts
}

Received: 14 February 2009 / Accepted: 27 September 2009 / Published online: 16 October 2009

(C) The Author(s) 2009. This article is published with open access at Springerlink.com

\begin{abstract}
Quantitative trait loci (QTL) studies provide insight into the complexity of drought tolerance mechanisms. Molecular markers used in these studies also allow for marker-assisted selection (MAS) in breeding programs, enabling transfer of genetic factors between breeding lines without complete knowledge of their exact nature. However, potential for recombination between markers and target genes limit the utility of MAS-based strategies. Candidate gene mapping offers an alternative solution to identify trait determinants underlying QTL of interest. Here, we used restriction site polymorphisms to investigate co-location of candidate genes with QTL for seedling drought stress-induced premature senescence identified previously in cowpea. Genomic DNA isolated from $113 \mathrm{~F}_{2: 8}$ RILs of drought-tolerant IT93K503-1 and drought susceptible CB46 genotypes was digested with combinations of EcoR1 and HpaII, Mse1, or Msp 1 restriction enzymes and amplified with primers designed from 13 drought-responsive cDNAs. JoinMap 3.0 and MapQTL 4.0 software were used to incorporate polymorphic markers onto the AFLP map and to analyze their association with the drought response QTL. Seven markers co-located with peaks of previously identified QTL. Isolation, sequencing, and blast analysis of
\end{abstract}

Communicated by H. T. Nguyen.

W. Muchero · P. A. Roberts $(\square)$

Nematology Department, University of California,

Riverside, CA 92521, USA

e-mail: philip.roberts@ucr.edu

W. Muchero

e-mail: wmuch001@ucr.edu

J. D. Ehlers

Botany and Plant Sciences Department,

University of California, Riverside, CA 92521, USA these markers confirmed their significant homology with drought or other abiotic stress-induced expressed sequence tags (EST) from cowpea and other plant systems. Further, homology with coding sequences for a multidrug resistance protein 3 and a photosystem I assembly protein ycf3 was revealed in two of these candidates. These results provide a platform for the identification and characterization of genetic trait determinants underlying seedling drought tolerance in cowpea.

\section{Introduction}

Drought tolerance is a genetically complex plant adaptation that involves multiple genes and pathways (Shinozaki and Yamaguchi-Shinozaki 2007). Gene expression studies have shown that expression levels of hundreds of genes are altered in response to drought stress (Ozturk et al. 2002; Talamé et al. 2006; Zhou et al. 2007). This alteration in expression level is also complex, varying widely depending on the magnitude and duration of drought stress (Dramé et al. 2007). Such complexity makes understanding the genetic mechanism of drought tolerance difficult. Similarly, breeding for drought tolerance is confounded by these complexities such that breeding is often conducted by phenotypic observation of physiological traits without an understanding of the genetic mechanism involved (Richards 2006). However, rapid improvements in quantitative trait loci (QTL) mapping technology have led to increased understanding of the genetic complexity and location within plant genomes of genetic determinants of traits conferring drought tolerance (Campos et al. 2004; Tuberosa and Salvi 2006).

Marker-assisted selection (MAS) application in breeding programs has benefited significantly from QTL studies that 
utilize readily available molecular markers to follow traits of economic importance (Francia et al. 2005; Ribaut and Ragot 2007; William et al. 2007). However, significant limitations exist in the utilization of MAS regardless of advances in this field. Most importantly, markers used in QTL studies and MAS programs typically lie outside gene regions with the consequence that genetic determinants are usually anonymous. Furthermore, the potential for recombination between molecular markers and the actual genes of interest may lead to mismatches between genotype and the desired phenotype (Collard et al. 2005). A potential solution is to clone QTL of interest in order to identify genetic determinants of the trait. However, this process is cumbersome requiring large amounts of resources and multiple collaborations to clone a single QTL (Salvi and Tuberosa 2005). Thus, only QTL with demonstrated stability over multiple environments and which offer significant economic benefits can be candidates for cloning (Campos et al. 2004). Nonetheless, rapid advances in the field of molecular biology and genomics offer alternative approaches to understanding the nature of genes underlying QTL of interest (Tuberosa and Salvi 2006). In drought tolerance studies, these advantages are complemented by a robust body of knowledge related to genetic pathways of responses to drought stress in model and non-model plant systems (Xiong et al. 2002; Zhu 2002; Bartels and Sunkar 2005; Tommasini et al. 2008). Conserved gene sequences across taxa as well as the increasing genome sequence information for model plant systems make it possible to identify and map candidate genes onto identified QTL regions (Borevitz and Chory 2004; Salentijn et al. 2007). Numerous studies have taken advantage of this information to successfully identify and map candidate genes onto drought tolerance QTL (Zheng et al. 2003; Nguyen et al. 2004; Tondelli et al. 2006).

In cowpea relatively little information is available on drought stress-related genes and pathways. A few studies have identified drought-responsive genetic elements that suggest roles by the jasmonic acid, lipid signaling, and abscisic acid pathways in cowpea response to drought. cDNAs homologous to alcohol dehydrogenase (CPRD12), dehydrin (CPRD22), NADPH-dependent aldehyde reductase (CPRD14), 12-oxo-phytodienoic acid reductase (CPRD8), lipoxygenase (CPRD46) (Iuchi et al. 1996a,b), and 9-cis-epoxycarotenoid (VuNCED1) (Iuchi et al. 2000) were isolated from a drought-tolerant cowpea genotype. Other cDNA transcripts, including a phospholipase D (VuPLD1) (El-Maarouf et al. 1999), a patatin-like galactolipid acyl hydrolase (VuPAT1) (Matos et al. 2001), phosphatidylinositol-specific phospholipase C (VuPI-PLC) (El-Maarouf et al. 2001), multicystanin (VuC) (Diop et al. 2004), ascorbate peroxidase (VuAPX) (D'Arcy-Lameta et al. 2006), and glutathione reductase (Contour-Ansel et al.
2006) were reported to be highly expressed in susceptible compared to tolerant cowpea genotypes. However, the role played by these specific genes has not been determined in cowpea. Restriction site polymorphism analysis using primers designed from some of these cDNAs revealed correlations between polymorphic fragments and different drought response phenotypes among a diverse set of 14 cowpea genotypes (Muchero et al. 2008). However, the molecular identity of these fragments was not determined in that study.

The purpose of this study was to map candidate genes using a cowpea recombinant inbred (RIL) population that was previously used to map seedling drought tolerance QTL (Muchero et al. 2009). This strategy will allow for the investigation of co-location of drought-responsive genes in relation to previously identified QTL and allow for the identification of candidate genes for further studies. Knowledge of the identity of genes within a QTL region will also offer opportunity for the identification of more candidate genes by investigating synteny between cowpea and model legume systems, where genomic information is more advanced. In this study, restriction polymorphism was used to map markers derived from 13 drought-responsive cDNA onto a genetic linkage map previously used to map seedling drought tolerance QTL.

\section{Materials and methods}

Plant material

A population of 113 cowpea [Vigna unguiculata (L) Walp.] $\mathrm{F}_{2: 8}$ recombinant inbred lines (RILs) developed by single seed descent from a cross between homozygous droughttolerant IT93K503-1 and susceptible CB46 genotypes were used in this study. The same RIL population had been used previously to construct a genetic linkage map using amplified fragment length polymorphism (AFLP) markers and to map quantitative trait loci (QTL) associated with seedling drought tolerance based on maintenance of stem greenness and recovery dry weight measurements (Muchero et al. 2009).

\section{Candidate gene selection}

Twelve candidate genes whose expression under drought stress had been characterized previously in cowpea were selected. These were CPRD8, CPRD12, CPRD14, CPRD22, CPRD46 (Iuchi et al. 1996a, b), phospholipase D, VuPLD1 (El-Maarouf et al. 1999), 9-cis-epoxycarotenoid dioxygenase, VuNCED1 (Iuchi et al. 2000), phosphatidylinositol-specific phospholipase C, VuPI-PLC (El-Maarouf et al. 2001), patatin-like galactolipid acyl 
hydrolase, VuPAT1 (Matos et al. 2001), multicystanin, VuC (Diop et al. 2004), and ascorbate peroxidase, VuAPX (D'Arcy-Lameta et al. 2006). The $\Delta^{1}$ pyrroline-5-carboxylate synthetase, which forms part of the proline biosynthesis pathway (Hu et al. 1992), was chosen based on a previous study that suggested an important role for proline accumulation in cowpea drought tolerance (Somal and Yapa 1998). In addition, 1-aminocyclopropane-1-carboxylate synthase (ACC synthase), a component of the ethylene pathway, was selected based on observed drought response phenotype that suggested a senescence-based response to drought stress in cowpea seedlings (Muchero et al. 2008). This response was similar to the one described in droughtstressed maize plants with altered ACC synthase expression (Young et al. 2004). The ethylene pathway was also reported to mediate senescence in other plant species (John et al. 1995; Buchanan-Wollaston et al. 2005).

\section{PCR primer design}

Design of new primers and sources of previously published primer sequences used in this study were described by Muchero et al. (2008). Briefly, primers based on CPRD8, CPRD12, CPRD14, CPRD22, CPRD46, and VuAPX cDNAs were designed from conserved regions identified after aligning the respective cowpea sequence with homologous sequences from Arabidopsis, pea (Pisum sativum), tobacco (Nicotiana tabacum), rice (Oryza sativa), and tomato (Solanum lycopersicum). Degenerate primers for $\mathrm{ACC}$ and P5C were based on non-cowpea sequences. P5C primers were designed based on the mothbean (Vigna aconitifolia) P5CS sequence (Hu et al. 1992) aligned with sequences from some of the species stated above, whereas the ACC degenerate primers were designed from conserved regions of ACC synthase genes from maize (Zea mays): EMBL accession AY359569, grape (Vitis vinifera): EMBL accession DQ679934, and tomato: EMBL accession U18055.

\section{Restriction site polymorphism}

DNA was isolated from young fresh trifoliates of greenhouse-grown RIL and parental genotypes. Briefly, leaf tissue was harvested from 3-week-old plants grown in 878-ml pots filled with UCMIX-B as described by Muchero et al. 2009. Pots were watered to capacity twice weekly. Young trifoliates were harvested, flash frozen in liquid nitrogen, and stored at $-85^{\circ} \mathrm{C}$ before DNA isolation. The DNeasy plant mini-kit (Qiagen, Valencia, CA, USA) was used for DNA isolation. DNA was quantified using a TD-360 Minifluorometer (Turner Designs, Sunnyville, CA, USA). DNA working solutions were made by diluting stock solution to $10 \mathrm{ng} / \mu \mathrm{l}$.
Since none of the primers described above revealed polymorphism between the two parental genotypes using undigested genomic DNA, a restriction site polymorphism-based protocol, similar in principle to the AFLP technique (Vos et al. 1995) was adopted. Polymorphisms were investigated first by digesting parental DNA with combinations of EcoR 1 and HpaII, Mse 1, or Msp 1 restriction enzymes (Promega, Madison, WI, USA). The EcoR1/ Mse 1 enzyme combination was chosen based on the AFLP protocol, and other enzyme combinations were chosen by testing on parental DNA and identifying combinations that revealed polymorphisms not revealed by the EcoR1/Mse 1 combination. Restriction digest reactions were carried out in $12.5 \mu \mathrm{l}$ reaction volume with $90 \mathrm{ng}$ genomic DNA in $9 \mu \mathrm{l}, 2.5 \mu \mathrm{l} 10 \times$ digestion buffer and $1 \mu \mathrm{l}$ enzyme mix and incubated overnight at $37^{\circ} \mathrm{C}$ in a Mastercycler ${ }^{\circledR}$ gradient thermocycler (Eppendorf AG, Hamburg, Germany). Each sample of restricted DNA was PCR-amplified using 13 primer pairs designed from 13 drought-responsive cDNAs described above. Briefly, $2.5 \mu \mathrm{l}$ of digested DNA solution was PCR-amplified in $12.5 \mu \mathrm{l}$ reaction volume. PCR mas-

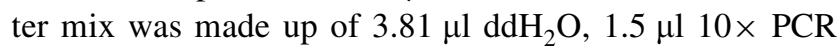
buffer (Invitrogen), $2 \mu 150 \mathrm{mM} \mathrm{MgCl}{ }_{2}$ (Invitrogen, Carlsbad, CA, USA), $0.38 \mu 110 \mathrm{mM}$ dNTP mix (Promega, Madison, WI, USA), $2 \mu 110 \mathrm{mM}$ primer mix, and $0.32 \mu \mathrm{l}$ Taq DNA Polymerase (Invitrogen, Carlsbad, CA, USA). PCR parameters were as follows: $95^{\circ} \mathrm{C}$ for $5 \mathrm{~min}$, and 39 cycles of $95^{\circ} \mathrm{C}$ for $30 \mathrm{~s}, 50^{\circ} \mathrm{C}$ for $30 \mathrm{~s}$, and $72^{\circ} \mathrm{C}$ for $90 \mathrm{~s}$. Mixture was kept at $72^{\circ} \mathrm{C}$ for $5 \mathrm{~min}$. Then $10 \mu \mathrm{l}$ amplified DNA plus $3 \mu \mathrm{l} 6 \times$ loading dye was electrophoresed on $3 \%$ agarose gel $(1.2 \mathrm{~g}$ agarose, $40 \mathrm{ml} 0.5 \times \mathrm{TBE}$, and $1.5 \mu$ ethidium bromide) in $0.5 \times$ TBE buffer for $3 \mathrm{~h}$ and visualized under ultraviolet light.

Restriction enzyme combinations and the respective primer-pairs that revealed polymorphisms between parental genotypes are given in Table 1. These were used to genotype 113 RILs as described above. Multiple polymorphic markers generated by the same primer pair were numbered according to decreasing size order and prefixed by the abbreviated name of the cDNA used in primer design.

\section{Linkage mapping}

Joinmap 3.0 (Van Ooijen and Voorrips 2001) was used to incorporate polymorphic markers on the existing AFLP map. The Kosambi mapping function (Kosambi 1944) was used to convert recombination frequencies to Centimorgan and a maximum recombination of $45 \%$ was used to assign markers to linkage groups. Map location was assigned to the linkage group with the highest association with the candidate gene marker at LOD scores $\geq 3$. Association with drought tolerance of markers that co-located with QTL was investigated by performing multiple-QTL model 


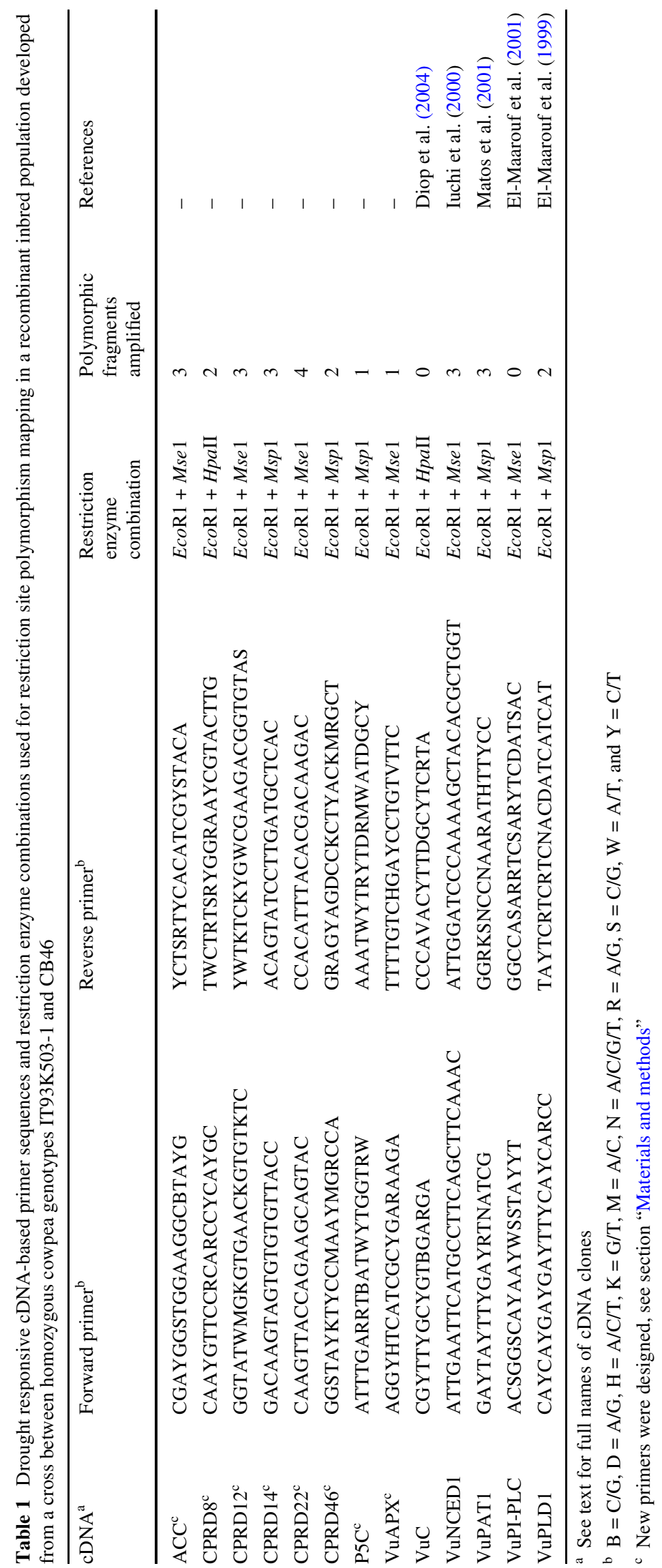


mapping (MQM) analysis with MapQTL 4.0 software (Van Ooijen et al. 2002) as described in Muchero et al. (2009). Polymorphic markers with insufficient linkage were analyzed for association with seedling drought-stress response as unmapped markers using the Kruskall-Wallis and interval mapping functions of MapQTL 4.0 software. Markers which mapped within QTL regions but were not associated with QTL peaks were not included in molecular analysis. Therefore, only markers associated with QTL peaks were considered for molecular characterization. Graphical representation of linkage groups and QTL was done using MapChart 2.2 software (Voorrips 2002).

\section{Cloning and sequencing}

Polymorphic markers that co-located with QTL peaks were excised from agarose gels and purified using the QIAquick $^{\circledR}$ gel extraction kit (Qiagen, Valencia, CA, USA) according to manufacturer's recommendation. In each case, DNA fragments were isolated from the parent genotype carrying the polymorphic fragment as well as from a random set of 10 RILs for molecular characterization. Parental and RIL DNA fragments were cloned separately. Purified DNA was cloned using the TOPO TA Cloning ${ }^{\circledR}$ system using chemical-competent TOP10F' E. coli cells (Invitrogen, Carlsbad, CA, USA). Briefly, $4 \mu 1$ PCR product was mixed with $1 \mu \mathrm{l} \mathrm{pCR}{ }^{{ }^{\circledR}} 2.1$ TOPO $^{\circledR}$ cloning vector and $1 \mu \mathrm{l}$ salt solution and incubated for 5 to $30 \mathrm{~min}$ at room temperature. TOP $10 \mathrm{~F}^{\prime}$ E. coli cells were thawed on ice and $6 \mu \mathrm{l}$ of the cloning reaction was pipetted into the cells and mixed gently. Cells were incubated in a water bath at $42{ }^{\circ} \mathrm{C}$ for $30 \mathrm{~s}$ and immediately placed on ice. Then $250 \mu \mathrm{l}$ manufacturer supplied S.O.C liquid media was added to the tubes and incubated for $1 \mathrm{~h}$ at $37^{\circ} \mathrm{C}$ with shaking at $200 \mathrm{rpm}$. Bacterial suspension was spread on selective liquid broth (LB) plates supplemented with $50 \mu \mathrm{g} / \mathrm{ml}$ ampicillin, $0.5 \mathrm{mM}$ IPTG, and $40 \mathrm{mg} / \mathrm{ml} \mathrm{X}$-gal. Plates were incubated overnight at $37^{\circ} \mathrm{C}$. Individual white colonies were picked and streaked on fresh selective LB plates and incubated overnight at $37^{\circ} \mathrm{C}$. White colonies were picked and incubated in $10 \mathrm{ml}$ LB liquid media overnight at $37^{\circ} \mathrm{C}$. Plasmids were isolated from bacterial cells using the QIAprep ${ }^{\circledR}$ miniprep kit (Qiagen, Valencia, CA, USA) as per manufacturer's recommendation. Confirmation of insert presence was done by restricting $2 \mu 1$ miniprep plasmid solution with EcoR 1 in $1 \mu \mathrm{l} 10 \times$ digestion buffer (Invitrogen, Carlsbad, CA, USA) and $6.8 \mu \mathrm{l}$ sterile water. Ten plasmids carrying inserts with the correct size for each of the seven restriction site polymorphism markers were sequenced at the University of California, Riverside Institute for Integrative Genome Biology (Riverside, CA).
DNA sequence analysis

Sequence electropherograms were viewed using FinchTV 1.4.0 (Geospiza, Seattle WA, USA). Homology between candidate gene markers and cowpea expressed sequence tags (ESTs) was investigated using HarvEST:Cowpea 1.05 database (http://www.harvest-web.org, http://harvest.ucr. edu/). Investigation of homology with other plant ESTs and coding sequences in the National Center for Biotechnology Information (NCBI) database was done using the Washington University (WU)-blast2-nucleotide database query web-site (Altschul et al. 1990). A cut-off threshold of 1e-05 was used in homology searches.

\section{Results}

Twenty-six polymorphic markers were generated from primers designed from 13 drought-responsive candidate genes. Of these, 13 markers did not have sufficient linkage to be placed on the map. Based on Kruskall-Wallis and interval mapping analysis, none of the unmapped markers showed consistent association with seedling drought-stress response phenotypes. Of the 13 markers that mapped successfully, six mapped outside the previously identified QTL regions for drought-stress response. The remaining seven markers, ACC-3, CPRD8-1, CPRD14-2, CPRD14-3, CPRD22-2, CPRD22-4, and VuPAT1-2 co-located with QTL Dro-5, Dro-5, Dro-3, Dro-1, Dro-2, Dro-4, and Dro-3, respectively (Table 2, Fig. 1). DNA fragment length ranged in size from 139 to $788 \mathrm{bp}$ for the seven markers targeted for sequencing (Table 2). MQM analysis confirmed the association between these markers and the respective QTL. Examples of LOD traces for each candidate gene and QTL association are given in Fig. 1a-d. CPRD14-3 mapped in a region that showed consistent association with seedling drought-stress response but did not meet the LOD significance threshold calculated at the 0.05 significance level (Fig. 1a). The remaining markers mapped in QTL regions that were highly associated with drought stress responsebased LOD scores determined by MQM analysis (Fig. 1b-d). Additional definitions of the QTL regions are given in supplementary tables in (Muchero et al. 2009).

Isolation, sequencing, and blast searches revealed homology of all seven QTL-associated markers to cowpea ESTs isolated from drought-stressed and non-stressed tissue below the $1.0 \mathrm{e}-05$ threshold $(1.5 \mathrm{e}-32 \leq E \leq 4.2 \mathrm{e}-10)$ (Table 3). Further, five of these had significant homology to water deficit stress-induced ESTs from other plant systems (Table 3). Marker ACC-3, derived from the susceptible CB46 parent, was homologous to a grape (Vitis vinifera) water deficit-induced EST with an $E$-value of 7.1e-93. In addition, this marker had homology with a common bean 
Fig. 1 Map positions of restriction site polymorphism markers (bold and magenta) co-locating with drought-induced premature senescence QTLs highlighted by LOD traces (solid green lines) generated from multiple-QTL model mapping analysis. a linkage group 1, b linkage group 2, $\mathbf{c}$ linkage group 3, and d linkage group 5 of Muchero et al. (2009). Vertical broken lines represent LOD thresholds calculated at the 0.05 significance level
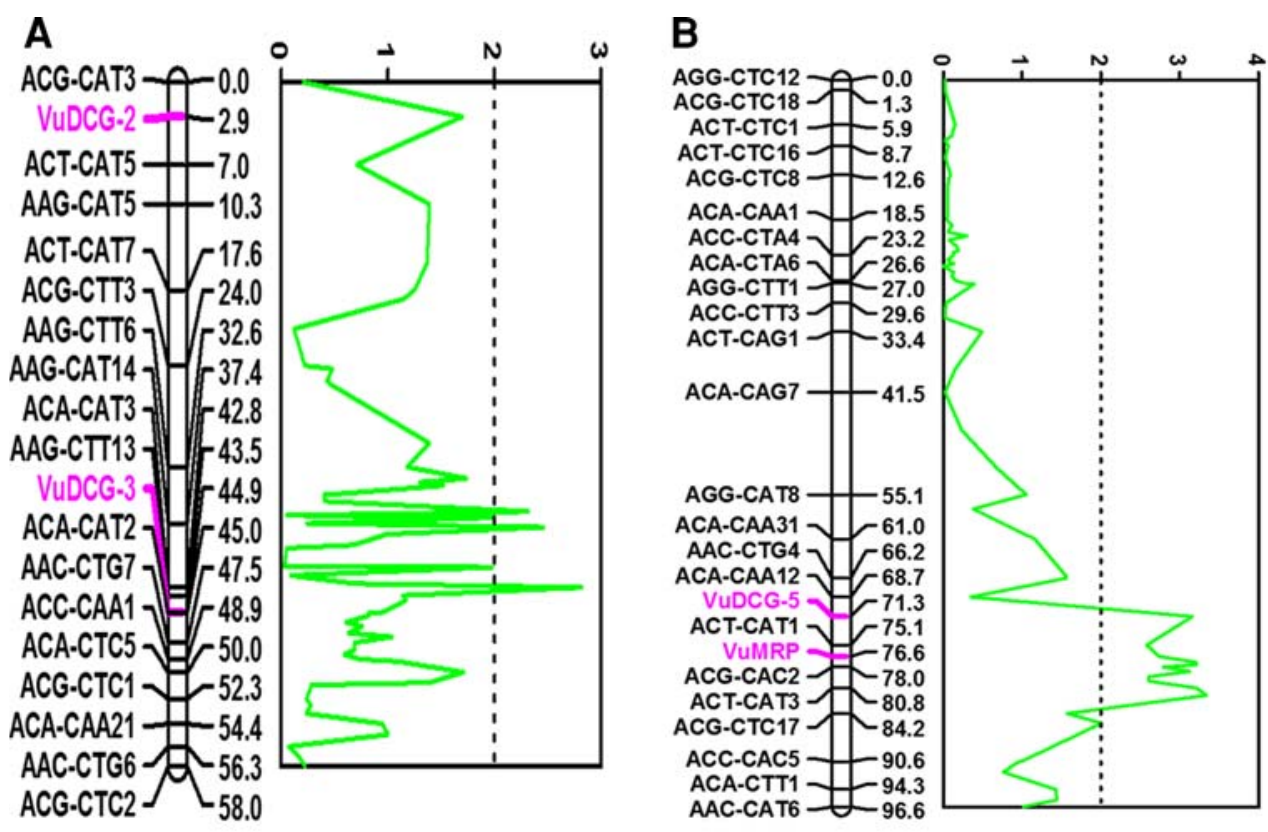

C

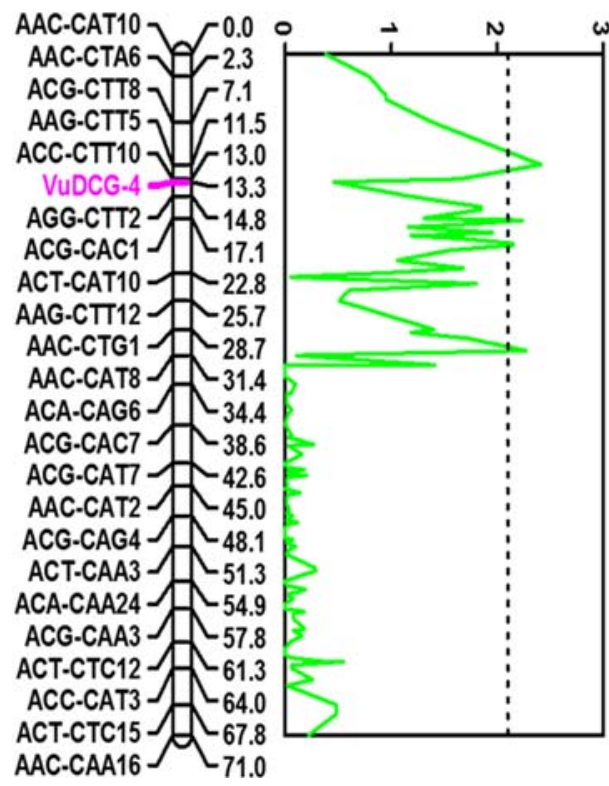

D

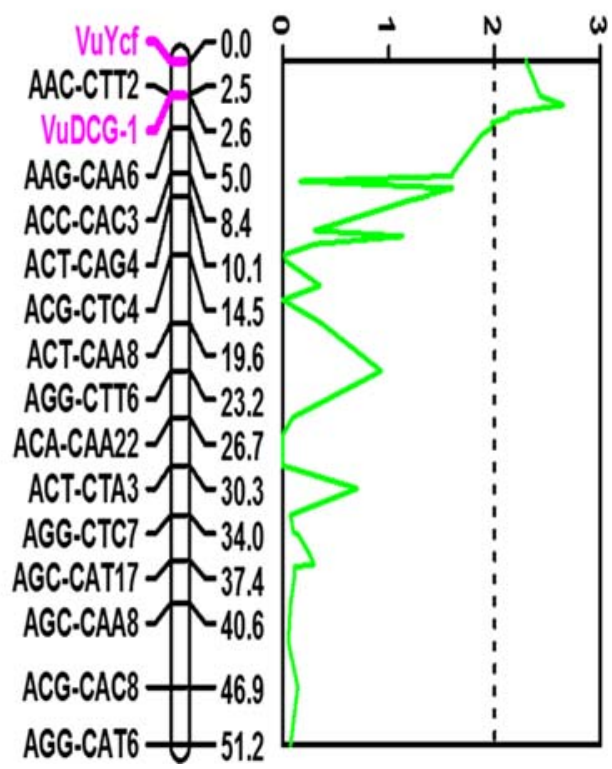

(Phaseolus vulgaris) sequence coding for a photosystem 1 assembly protein ycf3 $(E=1.3 \mathrm{e}-18)$. Hence, the candidate gene was designated Vigna unguiculata photosystem I assembly protein ycf (VuYCF) (Table 2). CPRD8-1 which was present in the tolerant IT93K503-1 genotype, was homologous $(E=4.7 \mathrm{e}-83)$ to an EST isolated from water deficit-stressed soybean (Glycine max) and also to a grape sequence coding for a hypothetical protein $(E=7.5 \mathrm{e}-29)$ (Table 3). Since the soybean EST and grape coding sequences were not annotated, polymorphic fragment CPRD8-1 was designated as Vigna unguiculata drought candidate gene 1 (VuDCG-1), and the same designation process was adopted for the remaining four candidate genes that had homology to unannotated ESTs and coding sequences (Table 2). The tolerant parent-derived CPRD14-2 was homologous $(E=1.7 \mathrm{e}-49)$ to a cold stress-induced EST from strawberry (Fragaria vesca). BLAST searches targeting coding sequences revealed significant homology of CPRD14-2 with a maize (Zea mays) multidrug resistance-associated protein 3 (1.0e-39) (Table 3) and was designated as Vigna unguiculata multidrug resistance-associated protein (VuMRP) (Table 2). CPRD22-4 (VuDCG-4), derived from tolerant IT93K503-1, and VuPAT1-2 (VuDCG-5), derived from susceptible CB46 parent, were homologous to a salt-stressed Fragaria vesca EST $(E=6.6 \mathrm{e}-07)$ and a water deficit stress-induced EST from 
Table 2 Restriction site polymorphism markers co-locating with seedling drought tolerance QTL in a cowpea recombinant inbred population developed from a cross between homozygous genotypes IT93K503-1 and CB46

\begin{tabular}{lllllcc}
\hline $\begin{array}{l}\text { Candidate } \\
\text { gene }^{\mathrm{a}}\end{array}$ & $\begin{array}{l}\text { Polymorphic } \\
\text { marker }\end{array}$ & $\begin{array}{l}\text { Muchero et al. (2008) } \\
\text { designation }\end{array}$ & $\begin{array}{l}\text { Fragment } \\
\text { size }^{\mathrm{b}}\end{array}$ & $\begin{array}{l}\text { Drought } \\
\text { QTL }^{\mathrm{c}}\end{array}$ & $\begin{array}{l}\text { Map } \\
\text { position (cM) }^{(\mathrm{c})}\end{array}$ & $\begin{array}{l}\text { QTL } \\
\text { interval }^{\mathrm{c}}\end{array}$ \\
\hline VuYcf & ACC-3 & ACC-2 & 208 & Dro-5 & 0.0 & $0-64.9$ \\
VuDCG-1 & CPRD8-1 & CPRD8-1 & 485 & Dro-5 & 2.6 & $0-64.9$ \\
VuMRP & CPRD14-2 & CPRD14-1 & 788 & Dro-3 & 76.6 & $55.2-97.7$ \\
VuDCG-2 & CPRD14-3 & CPRD14-2 & 531 & Dro-1 & 2.9 & $0.0-76.6$ \\
VuDCG-3 & CPRD22-2 & CPRD22-2 & 381 & Dro-2 & 85.3 & $78.2-99.1$ \\
VuDCG-4 & CPRD22-4 & - & 139 & Dro-4 & 13.3 & $4.3-68.5$ \\
VuDCG-5 & VuPAT1-2 & PAT-2 & 293 & Dro-3 & 71.3 & $55.2-97.7$ \\
\hline
\end{tabular}

${ }^{a}$ VuDCG Vigna unguiculata drought candidate gene, VuYCF Vigna unguiculata photosystem I assembly protein ycf, VuMRP multidrug resistance-associated protein

b Polymorphic marker size in base pairs

${ }^{c}$ Refer to supplementary Table in Muchero et al. 2009

d Marker was not described in the Muchero et al. 2008

Table 3 DNA sequence homology of restriction site polymorphism markers co-locating with seedling drought tolerance QTL in a cowpea recombinant inbred population developed from a cross between homozygous genotypes IT93K503-1 and CB46

\begin{tabular}{|c|c|c|c|c|c|}
\hline $\begin{array}{l}\text { Candidate } \\
\text { gene }^{\mathrm{a}}\end{array}$ & $\begin{array}{l}\text { EMBL } \\
\text { accession } \\
\text { number }\end{array}$ & $\begin{array}{l}\text { Homologous } \\
\text { cowpea EST, } \\
E \text {-value }\end{array}$ & $\begin{array}{l}\text { Homologous plant } \\
\text { EST, } E \text {-value }\end{array}$ & $\begin{array}{l}\text { Coding sequence } \\
\text { homology, } E \text {-value }\end{array}$ & $\begin{array}{l}\text { EMBL } \\
\text { accession } \\
\text { number }\end{array}$ \\
\hline VuYCF & FM991890 & FC462222, 1.5e-34 & $\begin{array}{l}\text { DT036854 water deficit-stressed } \\
\text { Vitis vinifera } \mathrm{EST}, 7.1 \mathrm{e}-93\end{array}$ & $\begin{array}{l}\text { Phaseolus vulgaris photosystem } \\
\text { I assembly protein ycf } 3,1.3 \mathrm{e}-18\end{array}$ & ABW22791 \\
\hline VuDCG- $1^{\mathrm{a}}$ & FM991891 & FF552859, $1.7 \mathrm{e}-18$ & $\begin{array}{l}\text { CX702472 water deficit stressed } \\
\text { Glycine max EST, } 4.7 \mathrm{e}-83\end{array}$ & $\begin{array}{l}\text { Vitis vinifera hypothetical } \\
\text { protein, } 7.5 \mathrm{e}-29\end{array}$ & CA070310 \\
\hline VuMRP & FM991892 & FC456737, 1.8e-56 & $\begin{array}{l}\text { DY } 674830 \text { cold-stressed } \\
\quad \text { Fragaria vesca } \mathrm{EST}, 1.7 \mathrm{e}-49\end{array}$ & $\begin{array}{l}\text { Zea mays multidrug resistance- } \\
\text { associated protein } 3,1.0 \mathrm{e}-39\end{array}$ & CAW45311 \\
\hline VuDCG-2 & FM991893 & FG885319, 2.6e-12 & - & - & \\
\hline VuDCG-3 & FM991894 & FF403513, 4.2e-10 & - & - & \\
\hline VuDCG-4 & FM991895 & FG934687, 5.6e-14 & $\begin{array}{l}\text { EX660997 salt-stressed } \\
\quad \text { Fragaria vesca } \text { EST, 6.6e-07 }\end{array}$ & $\begin{array}{l}\text { Vitis vinifera hypothetical } \\
\text { protein, } 2.9 \mathrm{e}-06\end{array}$ & CAO43929 \\
\hline VuDCG-5 & FM991896 & FG843420, 5.5e-11 & $\begin{array}{l}\text { DT039173 water deficit-stressed } \\
\text { Vitis vinifera } \text { EST, } 2.4 \mathrm{e}-05\end{array}$ & $\begin{array}{l}\text { Vitis vinifera hypothetical } \\
\text { protein } 3.2 \mathrm{e}-05\end{array}$ & CAN76904 \\
\hline
\end{tabular}

${ }^{a}$ VuYCF Vigna unguiculata photosystem I assembly protein ycf, VuDCG Vigna unguiculata drought candidate gene, VuMRP Vigna unguiculata multidrug resistance-associated protein

Vitis vinifera $(E=2.4 \mathrm{e}-05)$, respectively. Both of these markers were also homologous to Vitis vinifera hypothetical protein coding sequences (Table 3 ). Candidate markers CPRD14-3 (VuDCG-2), from tolerant IT93K503-1, and CPRD22-2 (VuDCG-2), from susceptible CB46, did not have significant matches with either ESTs or coding sequences from other plant systems (Table 3).

\section{Discussion}

Molecular markers, such as AFLPs, RAPDs, and SSRs have facilitated genome-based studies of complex traits, such as drought tolerance through QTL analysis (Collard et al. 2005). However, the limitation imposed by the molecular anonymity of such markers and the observation that they typically tag non-gene regions means that prohibitive amounts of resources need to be invested to gain insight into the genetic structure underlying such QTL (Salvi and Tuberosa 2005). The preponderance of genomic sequence information from model plant systems allows inference to be made about the genomic structure of nonmodel plant systems based on synteny arising from evolutionary relatedness (Borevitz and Chory 2004; Salentijn et al. 2007). In addition, progress made in characterizing gene networks involved in plant response to drought stress provides resources for the informed selection of candidate genes for study in non-model plant systems (Xiong et al. 2002; Zhu 2002; Bartels and Sunkar 2005). To this end, candidate gene mapping provides an approach to identify 
gene-derived landmark sequences for use in comparative genomic studies aimed at characterizing the genetic structure underlying complex QTL in non-model plants.

In this study we investigated the potential for candidate gene mapping in identifying gene-derived molecular markers co-locating with drought stress-induced premature senescence QTL in cowpea. As a non-model crop that is considered an "orphan crop", genomic resources in cowpea are relatively lacking (Kaga et al. 2005). Thirteen restriction site polymorphism markers mapped successfully and seven of these co-located with AFLP-based QTL identified previously in the RIL population exposed to seedling drought stress (Muchero et al. 2009). Blast searches showed that all seven candidate gene markers were homologous to sequences isolated from cowpea or other plant systems under drought or abiotic stress. However, these DNA fragments did not show homology with sequences that were used in primer design. This may be due to the use of degenerate primers resulting in unspecific amplification for ACC-, CPRD8-, and VuPAT1-derived primers. In addition, the low annealing temperature of $50^{\circ} \mathrm{C}$ may have allowed the amplification of close but unrelated sequences. The relatedness of parent cDNA sequences to CPRD8-1 (VuDCG-1), CPRD14-3 (VuDCG-2), CPRD22-2 (VuDCG-3), CPRD224 (VuDCG-4), and VuPAT1-2 (VuDCG-5) which revealed homology to uncharacterized ESTs cannot be determined conclusively without further studies.

However, polymorphism patterns and fragment sizes were highly reproducible from the previous study that used the same primers and genotyping protocol to characterize a diverse set of 14 cowpea genotypes (Muchero et al. 2008). This was with the exception of candidate marker CPRD224 (VuDCG-4), which was omitted from the previous study. Further, the fidelity of the protocol in targeting these polymorphisms was confirmed by sequencing multiple clones to rule out the presence of same-size but molecularly different fragments. In each case, the molecular identity of the polymorphic fragment from parental genotypes was characterized separately from homologous fragments pooled from RILs.

The co-location of these markers with seedling drought QTL as well as homology with drought responsive ESTs suggest that these markers were derived from genes that may be involved in cowpea response to drought stressinduced premature senescence. Most importantly, six out of the seven markers were closely associated with QTL peaks based on MQM analysis (Fig. 1), providing additional support for them as candidate trait determinants for seedling drought tolerance in cowpea. In addition, homology of VuYCF and VuMRP to the photosystem 1 assembly protein $\mathrm{ycf3}$ and multidrug resistance-associated protein (MRP) 3, respectively, which have been shown to mediate oxidative stress-induced leaf senescence, suggests that the candidate markers may tag important genes for cowpea response to drought stress.

The multidrug-resistance protein 3 that was homologous to VuMRP candidate gene and whose marker was absent from the drought-stress susceptible CB46 parent, is a member of the membrane-associated $\mathrm{ABC}$ transporters that are involved in the regulation of guard cells (Klein et al. 2003) and cellular detoxification (Klein et al. 2004). The importance of MRPs in regulating guard cells and therefore, stomatal conductance, was demonstrated by Klein et al. (2004) who reported the deregulation of stomatal opening and enhanced drought susceptibility in water deficit-stressed Arabidopsis thaliana plants with a knockout mutation in one of the MRP genes. This may suggest a parallel mechanism in cowpea, where presence of the susceptibility allele results in less efficient regulation of stomata under drought stress leading to enhanced drought-stress susceptibility.

The ycf3 gene, homologous to the VuYCF drought candidate marker derived from drought-stress susceptible CB46 parent, encodes a protein that plays an integral role in the assembly of photosystem 1 complex in chloroplasts (Naver et al. 2001). The differential regulation of ycf3 expression has been reported in senescing plants exposed to oxidative stress (Vranová et al. 2002) and salt stress (Sattosanto et al. 2004). Homologous transcripts have also been isolated from ripening grape berry plasma membranes (Zhang et al. 2008). Fruit ripening and plant tissue senescence have been demonstrated to involve related genetic and hormonal pathways (Borovsky and Paran 2008). The specific contribution of ycf3 toward drought tolerance has not been determined, however, a potential role is suggested by its importance in the assembly of the photosystem I antenna, which plays a critical role in the first stage of light harvesting for photosynthesis. Genotypes that possess the ability to maintain a functional ycf3 gene under drought or other oxidative stresses may be able to maintain higher rates of photosynthesis compared to genotypes in which ycf3 function is lost leading to impaired light harvesting under similar conditions.

Although the association of individual markers with drought-stress susceptible or tolerant parental genotype may offer insight into the potential contribution of each candidate gene toward cowpea response to drought stress, such inference is hindered by the complexity of inheritance of the drought response mechanism as described before (Muchero et al. 2009). Specifically, observation of transgressive segregants for both susceptibility and tolerance during QTL analysis suggested that the tolerant genotype also contributed alleles that negatively influenced drought tolerance, and/or that the susceptible parent contributed alleles that enhanced drought tolerance. Therefore, additional studies are needed to definitively address the potential role of each candidate gene toward cowpea response to seedling drought stress. 
The coincidence of these genes and other markers homologous to stress-induced ESTs with seedling drought response QTL may suggest important roles for these genes in cowpea. Although results of our study merit further molecular characterization of these candidate genes, the restriction site polymorphism-based candidate gene mapping technique may have its strongest utility in providing a genomic framework from which synteny can be investigated between cowpea and plant systems, such as Lotus japonicus, Medicago truncatula, Glycine max, and Arabidopsis thaliana where genomic resources are more advanced. This assertion recognizes studies in other crops that have indicated that tens or hundreds of genes may underlie each QTL interval (Salvi and Tuberosa 2005) and is underscored by the presence of some large QTL intervals in which some of the candidate markers mapped in this study. Saturating current QTL intervals with additional markers should refine QTL definition and association with the respective candidate gene-based markers.

Combined with saturation mapping, gene-derived molecular markers offer the potential to tag actual genetic determinants which will markedly improve the efficiency of marker-assisted selection (MAS) programs targeted at improving cowpea drought tolerance. By tagging the genetic determinants, the risk of recombination between molecular markers and the trait determinant, one of the major limitations in MAS, can be effectively eliminated.

With additional refinements especially regarding primer design and PCR amplification parameters, our study demonstrates the potential for mapping genes with known sequences from cowpea or other plant systems in genetic linkage maps, thereby providing a platform for further characterization of genomic regions carrying QTL of importance in breeding for improved cowpea productivity under marginal semi-arid conditions.

Acknowledgments We would like to thank Dr. T. J. Close for valuable insight and discussion and Dr. Rufina Hernandez-Martinez for technical assistance during the course of this study. This research was supported in part by the Bean/Cowpea Collaborative Research Support Program (USAID Grant no. GDG-G-00-02-00012-00) and the CGIAR Generation Challenge Program. The opinions and recommendations herein are those of the authors and not necessarily those of the funding agencies.

Open Access This article is distributed under the terms of the Creative Commons Attribution Noncommercial License which permits any noncommercial use, distribution, and reproduction in any medium, provided the original author(s) and source are credited.

\section{References}

Altschul SF, Gish W, Miller W, Myers EW, Lipman DJ (1990) Basic local alignment search tool. J Mol Biol 215:403-410

Bartels D, Sunkar R (2005) Drought and salt tolerance in plants. Crit Rev Plant Sci 24:23-58
Borevitz JO, Chory J (2004) Genomics tools for QTL analysis and gene discovery. Curr Opin Plant Biol 7:132-136

Borovsky Y, Paran I (2008) Chlorophyll breakdown during pepper fruit ripening in the chlorophyll retainer mutation is impaired at the homolog of the senescence-inducible stay-green gene. Theor Appl Genet 117:235-240

Buchanan-Wollaston V, Page T, Harrison E, Breeze E, Lim PO, Nam HG, Lin J-F, Wu S-H, Swidzinski J, Ishizaki K, Leaver CJ (2005) Comparative transcriptome analysis reveals significant differences in gene expression and signalling pathways between developmental and dark/starvation-induced senescence in Arabidopsis. Plant J 42:567-585

Campos H, Cooper M, Habben JE, Edmeades GO, Schussler JR (2004) Improving drought tolerance in maize: a view from industry. Field Crops Res 90:19-34

Collard BCY, Jahufer MZZ, Brouwer JB, Pang ECK (2005) An introduction to markers, quantitative trait loci (QTL) mapping and marker-assisted selection for crop improvement: the basic concepts. Euphytica 142:169-196

Contour-Ansel D, Torres-Franklin ML, Cruz de Carvalho MH, D'Arcy-Lameta A, Zuily-Fodil Y (2006) Glutathione reductase in leaves of cowpea: cloning of two cDNAs, expression and enzymatic activity under progressive drought stress, desiccation and abscisic acid treatment. Ann Bot 98:1279-1287

D'Arcy-Lameta A, Ferrari-Iliou R, Contour-Ansel D, Pham-Thi A, Zuily-Fodil Y (2006) Isolation and characterization of four ascorbate peroxidase cDNAs responsive to water deficit in cowpea leaves. Ann Bot 97:133-140

Diop NN, Kidrič M, Repellin A, Gareil M, D’Arcy-Lameta A, Thi ATP, Zuily-Fodil Y (2004) A multicystanin is induced by drought-stress in cowpea [Vigna unguiculata (L.) Walp.] leaves. FEBS Lett 577:545-550

Dramé KN, Clavel D, Repellin A, Passaquet C, Zuily-Fodil Y (2007) Water deficit induces variation in expression of stress-responsive genes in two peanut (Arachis hypogaea L.) cultivars with different tolerance to drought. Plant Physiol Biochem 45:236-243

El-Maarouf H, D'Arcy-Lameta A, Gareil M, Zuily-Fodil Y, Pham-Thi A (1999) Enzymatic activity and gene expression under water stress of phospholipase D in two cultivars of Vigna unguiculata L. Walp. differing in drought tolerance. Plant Mol Biol 39:1257-1265

El-Maarouf H, D' Arcy-Lameta A, Gareil M, Zuily-Fodil Y, Pham-Thi A (2001) Cloning and expression under drought of cDNAs coding for two PI-PLCs in cowpea leaves. Plant Physiol Biochem $39: 167-172$

Francia E, Tacconi G, Crosatti C, Barabaschi D, Bulgarelli D, Dall'Aglio E, Valè G (2005) Marker assisted selection in crop plants. PCTOC 82:317-342

Hu CA, Delauney AJ, Verma DPS (1992) A bifunctional enzyme ( $\Delta^{1}$-pyrroline-5-carboxylate synthetase) catalyzes the first two steps in proline biosynthesis in plants. Proc Natl Acad Sci USA 89:9354-9358

Iuchi S, Yamaguchi-Shinozaki K, Urao T, Shinozaki K (1996a) Characterization of two cDNAs for novel drought-inducible genes in the highly drought tolerant cowpea. J Plant Res 109:415-424

Iuchi S, Yamaguchi-Shinozaki K, Urao T, Terao T, Shinozaki K (1996b) Novel drought-inducible genes in the highly drought-tolerant cowpea: cloning of cDNAs and analysis of the expression of the corresponding genes. Plant Cell Physiol 37:1073-1082

Iuchi S, Kobayashi M, Yamaguchi-Shinozaki K, Shinozaki K (2000) A stress-inducible gene for 9-cis-epoxycarotenoid dioxygenase involved in abscisic acid biosynthesis under water stress in drought-tolerant cowpea. Plant Physiol 123:553-562

John I, Drake R, Farrell A, Cooper W, Lee P, Horton P, Grierson D (1995) Delayed leaf senescence in ethylene-deficient ACC-oxidase antisense tomato plants: molecular and physiological analysis. Plant J 7:483-490 
Kaga A, Vaughan DA, Tomooka N (2005) Molecular markers in Vigna improvement: Understanding and using gene pools. In: Lorz $\mathrm{H}$, Wenzel G (eds) Biotechnology in agriculture and forestry, vol 55. Molecular marker systems. Springer, New York, pp 171-187

Klein M, Perfus-Barbeoch L, Frelet A, Gaedeke N, Reinhardt D, Mueller-Roeber B, Martinoia E, Forestier C (2003) The plant multidrug resistance ABC transporter AtMRP5 is involved in guard cell hormonal signaling and water use. Plant J 33:119-129

Klein M, Geisler M, Suh SJ, Kolukisaoglu Ü, Azevedo L, Plaza S, Curtis MD, Richter A, Weder B, Schulz B, Martinoia E (2004) Disruption of AtMRP4, a guard cell plasma membrane ABCCtype $\mathrm{ABC}$ transporter, leads to deregulation of stomatal opening and increased drought susceptibility. Plant J 39:219-236

Kosambi DD (1944) The estimation of map distance from recombination values. Ann Eugen 12:172-175

Matos AR, D'Arcy-Lameta A, França M, Pêtres S, Edelman L, Kader J, Zuily-Fodil Y, Pham-Thi A (2001) A novel patatin-like gene stimulated by drought stress encodes a galactolipid acyl hydrolase. FEBS Lett 491:188-192

Muchero W, Ehlers JD, Roberts PA (2008) Seedling stage droughtinduced phenotypes and drought-responsive genes in diverse cowpea genotypes. Crop Sci 48:541-552

Muchero W, Ehlers JD, Close TJ, Roberts PA (2009) Mapping QTL for drought stress-induced premature senescence and maturity in cowpea [Vigna unguiculata (L.) Walp]. Theor Appl Genet 118:849-863

Naver H, Boudreau E, Rochaix J-D (2001) Functional studies of ycf3: its role in assembly of photosystem I and interaction with some of its subunits. Plant Cell 13:2731-2745

Nguyen TTT, Klueva N, Chamareck V, Aarti A, Magpantay G, Millena ACM, Pathan MS, Nguyen HT (2004) Saturation mapping of QTL regions and identification of putative candidate genes for drought tolerance in rice. Mol Genet Genomics 272:35-46

Ozturk ZN, Talamé V, Deyholos M, Michalowski CB, Galbraith DW, Gozukirmizi N, Tuberosa R, Bohnert HJ (2002) Monitoring large-scale changes in transcript abundance in drought-and saltstressed barley. Plant Mol Biol 48:551-573

Ribaut J, Ragot M (2007) Marker-assisted selection to improve drought adaption in maize: the backcross approach, perspectives, limitations and alternatives. J Exp Bot 58:351-360

Richards RA (2006) Physiological traits used in the breeding of new cultivars for water-scarce environments. Agric Water Manage 80:197-211

Salentijn EMJ, Pereira A, Angenent GC, Van der Linden CG, Krens F, Smulders MJM, Vosman B (2007) Plant translational genomics: from model species to crops. Mol Breeding 20:1-13

Salvi S, Tuberosa R (2005) To clone or not to clone plant QTLs: present and future challenges. Trends Plant Sci 10:297-304

Sattosanto JB, Gelli A, Blumwald E (2004) DNA array analyses of Arabidopsis thaliana lacking a vacuolar $\mathrm{Na}+\mathrm{H}+$ antiporter: impact of AtNHX1 on gene expression. Plant J 40:752-771

Shinozaki K, Yamaguchi-Shinozaki K (2007) Gene networks involved in drought stress response and tolerance. J Exp Bot 58:221-227
Somal TLC, Yapa PAJ (1998) Accumulation of proline in cowpea under nutrient, drought, and saline stresses. J Plant Nutr 21:2465-2473

Talamé V, Ozturk NZ, Bohnert HJ, Tuberosa R (2006) Barley transcript profiles under dehydration shock and drought stress treatments: a comparative analysis. J Exp Bot 58:229-240

Tommasini L, Svensson JT, Rodriguez EM, Wahid A, Malatrasi M, Kato K, Wanamaker S, Resnik J, Close TJ (2008) Dehydrin gene expression provides an indicator of low temperature and drought stress: transcriptome-based analysis of barley (Hordeum vulgare L.). Funct Integr Genomics 8:387-405

Tondelli A, Francia E, Barabaschi D, Aprile A, Skinner JS, Stockinger EJ, Stanca AM, Pecchioni N (2006) Mapping regulatory genes as candidates for cold and drought stress tolerance in barley. Theor Appl Genet 112:445-454

Tuberosa R, Salvi S (2006) Genomics-based approaches to improve drought tolerance of crops. Trends Plant Sci 11:405-412

Van Ooijen JW, Voorrips RE (2001) JoinMap 3.0: software for the calculation of genetic linkage maps. Plant Research International, Wageningen, The Netherlands

Van Ooijen JW, Boer MP, Jansen RC, Maliepaard C (2002) MapQTL ${ }^{\circledR}$ 4.0, software for the calculation of QTL positions on genetic maps. Plant Research International, Wageningen, the Netherlands

Voorrips RE (2002) MapChart: software for the graphical presentation of linkage maps and QTLs. J Hered 93:77-78

Vos P, Hogers R, Bleeker M, Reijans M, van de Lee T, Hornes M, Frijiters A, Pot J, Peleman J, Kuiper M, Zabeau M (1995) AFLP: a new technique for DNA fingerprinting. Nucleic Acids Res 23:4407-4414

Vranová E, Atichartpongkul S, Villarroel R, Van Montagu M, Inze D, Van Camp W (2002) Comprehensive analysis of gene expression in Nicotiana tabacum leaves acclimated to oxidative stress. Proc Natl Acad Sci USA 99:10870-10875

William HM, Trethowan R, Crosby-Galvan EM (2007) Wheat breeding assisted by markers: CIMMYT's experience. Euphytica 157:307-319

Xiong L, Schumaker KS, Zhu J (2002) Cell signaling during cold, drought, and salt stress. Plant Cell 14:S165-S183

Young TE, Meeley RB, Gallie DR (2004) ACC synthase expression regulates leaf performance and drought tolerance in maize. Plant J 40:813-825

Zhang J, Ma H, Feng J, Zeng L, Wang Z, Chen S (2008) Grape berry plasma membrane proteome analysis and its differential expression during ripening. J Exp Bot 59:2979-2990

Zheng BS, Yang L, Zhang WP, Mao CZ, Wu YR, Yi KK, Liu FY, Wu P (2003) Mapping QTLs and candidate genes for rice root traits under different water-supply conditions and comparative analysis across three populations. Theor Appl Genet 107:1505-1515

Zhou J, Wang X, Jiao Y, Qin Y, Liu X, He K, Chen C, Ma L, Wang J, Xiong L, Zhang Q, Fan L, Deng XW (2007) Global genome expression analysis of rice in response to drought and highsalinity stresses in shoot, flag leaf, and panicle. Plant Mol Biol 63:591-608

Zhu J (2002) Salt and drought stress signal transduction in plants. Annu Rev Plant Biol 53:247-273 